\title{
História e tempo. Ricoeur e a interpretação de Sein und Zeit
}

José Manuel Heleno

Em memória de João Paisana, direi, como o Rilke da Nona Elegia de Duino: «Também o caminhante não traz da encosta da montanha um punhado de terra para o vale, terra para todos indizivel, mas sim uma palavra adquirida, pura, a genciana amarela e azul».

1. É nosso propósito restringirmo-nos à análise que Ricoeur faz da obra magna de Heidegger, Sein und Zeit (SuZ), seguindo a argumentação que desenvolve na terceira parte de La Mémoire, L'histoire, L'oubli', intitulada "La condition historique" -, em particular no segundo capitulo ("Histoire et temps"; pp. 449-535), onde aborda, sob o signo de uma hermenêutica ontológica, a relação entre história e tempo.

Como afirma Ricoeur, é com Ser e Tempo, «um dos grandes livros do século $\mathrm{XX}$ » que, volens nolens, se terá de confrontar para ajuizar da importância da condição histórica do ser humano. No horizonte de todas as suas preocupaçôes perfila-se o enigma da "presença da ausência», isto é, a questão da memória e da história. Se visamos a "passeidade» (passéité) das coisas passadas e o futuro das coisas por vir, tal mostra que é o passado e o futuro enquanto tais que importa esclarecer. Ora, quer Santo Agostinho quer Husserl, centraram as suas perspectivas sobre o tempo no presente, embora partindo de uma distensão (Agostinho) ou de um jogo entre retenção e protenção (Husserl). Para o autor das Confissões o tempo distende-se entre um presente do passado (memória), um presente do presente (atenção) e um presente do futuro (expectativa). Ao fazer do presente o ponto de irradiação do tempo, Agostinho mostrava o seu fascínio por aquilo que alguns designam de «representação» ou metafisica da presença, conotada com a ideia de eternidade como um nunc stans, um presente eterno. Como veremos, Ricoeur reabre o debate sobre o tempo insistindo na necessidade de o deslocar, não apenas para «fora» do sujeito como reintroduzindo a noção de história no intuito de desafiar a metafísica da presença e a importância que Heidegger confere ao futuro.

1 Trata-se do último livro de Ricoeur (Paris, Éditions du Seuil, 2000). Cf. a nossa recensão a esta obra em Phainomenon, n. ${ }^{\circ}$, Lisboa, Edições Colibri. 
Em primeiro lugar, Ricoeur aceita o Dasein como «conceito ontológico de referência última» em SuZ. E acrescenta de imediato que a noção de Dasein deve ser inserida no contexto de uma antropologia filosófica, designadamente na noção de poder ou capacidade específica do ser do homem. No entanto, relembremos que Heidegger nunca cessou de criticar a «persistência das representações subjectivas saídas do cartesianismo» que teima em pensar Sein und Zeit a partir do modelo antropológico. A confiar em Frédérik de Towarnicki ${ }^{2}$, Heidegger deplorava o primado da consciência e a obsessão em «ler» o Dasein como uma «realidade humana». É neste espírito que critica a tradução francesa de Henry Corbin ao verter Dasein por «être là» ou «réalité humaine», quando traduzir Dasein por «ser-o-aí» (être-le-là) da existência estaria mais de acordo com a sua estrutura ontológica enquanto abertura para a liberdade (op. cit., p. 71). Se o Dasein não é o cogito; se o mundo não está na consciência, é sintomático que a questão da diferença ontológica tenha, nomeadamente em França, sido «anulada» ou até «apagada» - o que nos pode ajudar a compreender a leitura que Sartre faz de Heidegger e do «desencontro» entre ambos. É neste sentido que se pode dizer que Ricoeur herda uma leitura determinada de Heidegger, persistente em sectores de língua francesa.

No seguimento de Soi-même comme un autre, onde se via o homem como um ser capaz (como um poder falar, agir, narrar...) acentua-se em La Mémoire, l'histoire, l'oubli o "poder fazer memória». Contudo, no confronto com Heidegger começa-se por aceitar o Dasein como conceito prioritário, justamente porque ele mesmo se caracteriza pelo cuidado em relação às coisas que estão «à mão» (vorhanden) ou ao «alcance da mão» (zuhanden). Toda a pertinência ontológica do cuidado reside no facto de este não ser apenas uma instância teórica ou prática do Dasein, mas sim uma afeç̧ão do mesmo, lançado no mundo e aberto para os entes, tal como a angústia o indica. Ricoeur relaciona o cuidado com o «todo estrutural» (cf. SuZ, § 41 e 46), preparando assim a relação entre cuidado e morte.

É neste contexto que Ricoeur retoma a questão da diferença ontológica, ou seja, refere a distinção entre existenciários e existencial ${ }^{3}$ e afirma: «E por vezes difícil manter esta distinção, como os propósitos tidos mais à frente sobre a morte e o ser-para-a-morte o verificarão» (p. 451). De facto, a rejeição da distinção entre o nível ôntico e o nível ontológico - distinção fundamental para uma compreensão de Ser e Tempo -, é constantemente reiterada por Ricoeur, não em apenas em Temps et récit mas em textos anteriores, onde ressalta a necessidade de distinguir uma via curta de uma via longa na hermenêutica. Efectivamente, para o autor de Du texte à l'action, o momento epistemológico tem uma importância que Heidegger descurou, entranhando-se de forma radical na ontologia fundamental. Para Ricoeur, contudo, a via curta, ou seja, a ontologia da compreensão, não é capaz, por si só, de fundamentar a dimensão hermenêutica, devendo-se tomar em consideração o momento semântico e epistemológico que a via longa deve assumir. Veremos posteriormente que este é um aspecto que afasta decididamente os dois pensadores.

2 F. de Towarnicki, À la rencontre de Heidegger: Souvenirs d'un messager de la Forêt-Noire, Paris, Arcades/Gallimard, 1993.

3 Traduzimos as expressões francesas «existentiaux» e «existentiel» respectivamente por «existenciários» e «existencial». Relembremos, a propósito, as expressões alemãs, existenziale (existenciário), existenzialien (existenciários) e existenziell (existencial). Se, para Heidegger, a analítica existenciária é a ontologia fundamental, tal significa que, desde $S u Z$, a questão do sentido do ser tem como pressuposto a diferença ontológica. Todavia, só no curso do semestre de Verão de 1927, intitulado Os Problemas Fundamentais da Fenomenologia, se tematiza expressamente a diferença ontológica. 
É a noção de «carne» (chair) que permite, segundo Ricoeur, fazer a transição entre os existenciários que se organizam em torno do cuidado e as categorias, modos de ser das coisas. Com efeito, a noção de «carne» - «corpo animado»; «corpo que é meu» - é algo que $S u Z$ «esqueceu». Contrariamente a Husserl, que nas suas Meditações Cartesianas (Cf. Quinta Meditação) tentou pensar tal desiderato, Heidegger não articulou o «cuidado» com a «carne». Escreve Ricoeur: «A capacidade da Analítica do Dasein para reconhecer e ultrapassar esta dificuldade está ainda por demonstrar». Ora, se Ricoeur dá tanta importância a esta questão é porque ela permite tornar visível a incapacidade de sustentar a diferença ontológica, acabando por rejeitar a articulação entre Dasein e morte no pensamento heideggeriano. Com efeito, a «carne» mostra o poder ser do humano; o seu desejo - conatus, libido, afirmação. Pergunta então Ricoeur: «Como é que a morte se vem inscrever nesta relação à carne?» (p. 466). Ao ser desejo, vontade de viver, afirmação da vida, o Dasein é visto numa perspectiva que era, aparentemente, insuspeitável para Heidegger.

Se esta é a primeira consideração que Ricoeur refere a propósito do confronto que irá desenvolver com Heidegger, a segunda prende-se com a noção de temporalidade que "assinala a relação deste ser (Dasein) ao ser enquanto ser» (p. 452). É inegável que esta é uma das questões mais insistentes no debate entre Ricoeur e Heidegger. Relembremos Temps et récit e a preocupação em completar a visão fenomenológica do tempo com o tempo cosmológico. Se nessa altura havia a necessidade de apreender o tempo fora de um contexto subjectivo e fenomenológico que as perspectivas de Agostinho, Husserl ou Heidegger defendiam, trata-se agora de tentar apreender a temporalidade a partir da noção do passado, ou seja, de interrogar o modo como $S u Z$ pode eventualmente lidar com a noção de «representação do passado pela história», a qual remete, por maioria de razões, para a questão da memória. Trata-se, enfim, de saber porque é que Ser e Tempo «ignora o problema da memória e só episodicamente toca no do esquecimento» (p. 474).

Uma outra consideração pressupõe o desenvolvimento da questão que acabámos de referir. Com efeito, se a temporalidade heideggeriana articula futuro, passado e presente, interessa saber como é que a fenomenologia da memória e a epistemologia da história lidam com a «passeidade» (passéité), ou seja, com aquilo que é próprio do passado, mesmo que o façam de forma não temática. Poder-se-á efectivamente, ao lidarmos com a «passeidade», fazer abstracção do futuro? Poderá haver, por parte do historiador, um olhar inteiramente retrospectivo? (Cf. p. 453). Se assim for, então não se necessita de evocar o futuro ou, para citar uma das expressões fundamentais de La Mémoire, L'histoire, L'oubli, «a memória é do passado» (Aristóteles) - expressão que acentua vigorosamente a referência e a direcção da memória. Se o futuro é posto entre parênteses, tal ajuda a compreender

4 Também Bernard Schumacher, em "La mort comme la possibilité de l'impossibilité d'être. Une analyse critique de Heidegger" (Archives de Philosophie 62, 1999) defende um ponto de vista semelhante. Se Heidegger vê na morte a essência do "poder ser» do Dasein, o que faz com que a morte do outro possa apenas ser «assistida» e não vivida, importa interrogar se o Dasein não é, também, um ser que se caracteriza pelo desejo «existencial». Schumacher põe no mesmo plano esta tensão entre um Dasein em que a possibilidade da morte o acompanha sempre e um Dasein como um «ente substancialmente desejante». É neste sentido que o autor fala de um encontro "dialéctico entre a vida e a morte no seio da existência humana», de tal forma que há uma dupla constituição ontológica inscritas no coração do Dasein: a do "ser-para-a-morte e a do não-ser-para-a-morte». Relembremos que também Espinosa via na sabedoria uma meditação sobre a vida e não sobre a morte. 
como Husserl, por exemplo, nas suas lições sobre o tempo, fala essencialmente da retenção e apenas sumariamente da protenção, pois o autor fala dela «como se se tratasse de uma simetria reconhecida» (p. 453). Para Heidegger, é um facto que «o primado do futuro está implicado no tema do ser-para-a-morte» (p. 464); ao querer ser um todo, o Dasein faz da morte o seu possível mais próprio. Ora, como lidará o historiador com este ponto de vista?

Considerando que o historiador não se pode abstrair do futuro, Ricoeur quer prová-lo a partir da reflexão que desenvolverá em torno da noção de temporalidade em SuZ. Se é verdade que «a temporalidade constitui a pré-condição existenciária da referência da memória e da história ao passado» (p. 454), há, em Heidegger, um acentuar do futuro como «resolução antecipante». Num trecho que nos parece essencial, Ricoeur escreve: «Podemos, todavia, resistir à sugestão que a orientação para o futuro seria mais fundamental ou, como diremos mais à frente, mais autêntica e mais originária que a orientação para o passado e para o presente, devido à densidade ontológica do ser-para-a-morte que veremos estreitamente ligada à dimensão do futuro; simetricamente, podemos resistir à tendência para reduzir a relação ao presente à preocupação atarefada: o espanto, o sofrimento e a fruição e também a iniciativa são grandezas notáveis do presente que uma teoria da acção e, por implicação, uma teoria da história, têm de tomar em consideração» (p. 454). Ao primado do futuro e à ideia de ser-para-a-morte, Ricoeur acabará por contrapor o ser «apesar-da morte» que Lévinas também referia. Decorre deste pressuposto que a resposta à angústia é a alegria de viver. Quando Ricoeur se interroga: «A angústia que põe o seu selo sobre a ameaça sempre iminente do morrer não mascara a alegria do ímpeto de viver?» (p. 465), a sua resposta só pode ser afirmativa. Se a morte é apenas uma questão existencial (existentiel) de Heidegger, isto é, uma resolução de Heidegger enquanto homem face ao morrer, tal significa que Ricoeur está interessado em sublinhar que a morte é «um destino inelutável do corpo-objecto». Trata-se, por isso, de uma questão biológica que remete para um ter de morrer inevitável. Acresce que a perspectiva heideggeriana da morte impedirá a compreensão da morte dos outros - dos que nos são próximos e não só -, esses que, segundo a leitura que Ricoeur faz de Heidegger, são vistos sob o prisma da inautenticidade.

É assim que ao propor-se desafiar pressupostos fundamentais de $S u Z$, Ricoeur quer mostrar que há uma hierarquia temporal originária no texto de Heidegger que importa discutir. Deste modo, e para além da temporalidade propriamente dita que consiste numa orientação do Dasein em direcção ao futuro, importa referir a historicidade, o intervalo entre o nascer e o morrer e onde prevalece, de certo modo, uma referência ao passado que privilegia a história e a memória, e a intratemporalidade, onde o presente e as coisas manipuláveis que supõem o conceito vulgar de tempo, são preocupações fundamentais do Dasein. O que é essencial para Ricoeur é que estes níveis da temporalidade possuem uma ordem decrescente de autenticidade e de «originaridade» (originarité) à medida que nos aproximamos do conceito vulgar do tempo.

Se é verdade que Ricoeur, no contexto da sua reflexão, se deveria preocupar apenas com a Geschichteichkeit - que alguns tradutores preferem verter por «historialidade» (historialité) -, é a temporalidade tomada globalmente que se deve tomar em consideração, justamente porque ela permite ajuizar em profundidade o debate que o historiador pode manter com o filósofo a propósito da noção de «passeidade». É deste modo que Ricoeur anota algumas «imprecisões» em SuZ, designadamente na noção de «autenticidade», de «resolução antecipante» ou até de «consciência» (Gewissen) - expressões que não estariam suficientemente 
esclarecidas no texto de Heidegger. Ao abrir o debate entre o historiador e o filósofo, Ricoeur acabará por defender que as imprecisões de $S u Z$ mostram a necessidade de ultrapassar a primazia do futuro tal como a Heidegger a perspectiva - e é neste contexto que Ricoeur, uma vez mais, e no seguimento de Temps et récit e de Soimême comme un autre, fala em natalidade e relembra Hanna Arendt.

Se a noção de futuro é retirada do seu pedestal, também a noção de «ser-para-a-morte» merece os reparos de Ricoeur. Afinal, não é só a morte própria que importa, pois há, para além da morte de si mesmo, a morte dos que nos são próximos e a dos outros. Esta atribuição múltipla do morrer e o abandono da primazia do futuro é o que permitirá olhar de outro modo o passado. Heidegger, ao falar num «passado terminado» (passé révolu) não tomou em consideração o «tendo sido» (ayant été), estando este último mais próximo do viver efectivo e da repetição que, incessantemente, nos permite retomar o passado para viver e compreender o presente. Se «os mortos de hoje são os vivos de ontem» (p. 495), tal indica a preocupação pelos seres que agem e sofrem. São estes seres, precisamente, que o historiador homenageia, fazendo do acto de escrever um rito funerário. Ao escrever a história, o historiador sepulta os seus mortos, como o defenderá Michel de Certeau. Ao insistir que a história só era possível porque o Dasein era histórico no fundo do seu ser, Heidegger poderia e deveria ser mais sensivel ao trabalho da memória e da história, justamente o que nos faz dialogar com os outros que são, afinal, uma parte de nós próprios. Em vez disso, Heidegger vê o passado «terminado» como uma forma «inautêntica de temporalidade, tributária do conceito vulgar do tempo, simples soma de agoras evanescentes» (p. 474).

Também Reinhart Koselleck, um autor que Ricoeur cita com frequência, defende a propósito do octogésimo quinto aniversário de Gadamer, numa conferência intitulada "História e Hermenêutica"s, uma perspectiva crítica sobre a noção de história em Heidegger. Escreve, por exemplo: «Mas na análise (de Heidegger) da sua determinação da finitude intercalaram-se, contudo, numerosas categorias e interpretações legiveis antropologicamente, susceptiveis de serem aperfeiçoadas e ampliadas, por muito que o próprio Heidegger se esforçasse por se opor a semelhante "antropologização"» (op. cit., p. 72). E o autor exemplifica referindo-se a inúmeras expressões onde são visíveis essa «antropologização», como Sorge, Angst, Schuld, Gewissen, etc. Considerando que há, em Sein und Zeit, uma insuficiência na determinação da história a partir de um projecto como aquele que Heidegger desenvolve, inteiramente assente no Dasein, Koselleck expõe cinco categorias «transcendentais» que possibilitam a história e mostram, assim, a insuficiência das modalidades existenciárias desenvolvidas no homem como Dasein. Expostas sob a forma de antítese, opõe-se o «ter que morrer» ao «poder matar», tal como o amigo ao inimigo, o interior ao exterior, a morte à natalidade ou ao generativo e o senhor ao escravo. A impossibilidade de fundamentar a história na mera finitude do Dasein, significa que os cinco pares de categorias referidas se podem revelar profícuas para a compreensão de qualquer história possível, pois não há história humana que não tenha as suas marcas.

2. No intuito de elucidar o confronto entre Ricoeur e Heidegger, é premente recorrer ao texto do filósofo alemão para ajuizar da leitura que Ricoeur faz do mesmo.

5 Cf. R. Koselleck e Hans-George Gadamer, Historia y hermenéutica, Barcelona, Ediciones Paidós, 1997. 
Relembremos que Sein und Zeit ${ }^{6}$ se inicia insistindo na necessidade de repetir expressamente (ausdrücklichen wiederholung) a pergunta em direcção ao ser (§1). Ao emudecer (verstummen), depois de Platão e Aristóteles, a pergunta deve ser tematicamente recolocada. A sua trivialidade, longe de provar a sua clareza, prova antes a sua obscuridade. Há assim preconceitos que impedem interrogar o sentido do ser, como dizer que se trata de um conceito universal, indefinível ou até o mais compreensível dos conceitos. Heidegger quer mostrar que a pergunta carece de direcção, rejeitando liminarmente a convicção que se trata de um erro metódico voltar a colocar a questão. Ora, uma pergunta deve «deixar ver adequadamente através de si» (angemessenen Durchsichtgkeit); deve ser uma pergunta assinalada (ausgezeichnete), designadamente a pergunta que interroga pelo ser, pergunta insigne. Se todo o perguntar é um procurar, então a direcção do procurar vem do procurado. É ele, na verdade, que dirige a questão; é ele que se interroga para que o possamos traduzir em conceitos. Escreve Heidegger que, «de certo modo, o sentido do ser já deve estar disponível (verfügbar)» (§2), justamente porque nos movemos sempre e já numa compreensão dele mesmo.

É convicção nossa que as páginas iniciais de SuZ nos lançam de imediato na questão ontológica. Ao dizê-lo queremos acentuar que Heidegger se afasta de um projecto antropológico - questão que tem a sua importância no confronto com a perspectiva ricoeuriana. Todavia, só incidindo a nossa análise na relação entre tempo e historicidade se pode revelar, de forma concreta, aquilo que afasta os dois pensadores no que concerne à noção de história. O capítulo cinco da segunda secção de $S u Z$ aborda directamente a questão referida. É ele que merece a nossa detenção. Não podemos, porém, compreendê-lo, se não começarmos por referenciar os temas fundamentais da segunda secção, intitulada "Dasein e Temporalidade".

Se o Dasein é cuidado, tal significa que existe lançado no mundo e é de cada vez ele mesmo. A «existência» não pode, aliás, ser compreendida de outro modo. Ora, se toda a investigação ontológica é interpretação, ela mesma possui o seu «ter», «ver» e «conceber prévio». Ao existir, o Dasein é um poder-ser, próprio ou impróprio. Com a questão da temporalidade, importa a Heidegger efectuar uma exegese do Dasein enquanto modo de ser próprio, isto é, ser um todo.

É neste contexto que surge a necessidade de mostrar que o fim do Dasein é a morte, isto é, só uma análise existenciária da mesma permitirá compreender a importância da temporalidade. Escreve Heidegger (§ 45) que «o fundamento ontológico original da existenciaridade do Dasein é a temporalidade. Só partindo dela se torna existenciariamente compreensível a articulada totalidade estrutural do ser do Dasein, do cuidado». De facto, é com o cuidado que se compreende o que é «ter tempo» ou «empregar o tempo», pois é ele que permite dar a ver a temporalidade. Não é por acaso que Heidegger termina $S u Z$ insistindo que é na temporalidade que se revela o sentido do cuidado (cf. § 83). É deste modo que, a um sujeito fechado sobre si mesmo, se contrapõe um ente, o Dasein, que está fora de si e tem, portanto, uma estrutura «ekstática». Longe de o Dasein estar no tempo, ele é, ao invés, tempo, o que afasta Heidegger de Husserl quando este pretendia pensar o tempo na consciência.

As nossas primeiras observações, no intuito de confrontar as perspectivas de Ricoeur e Heidegger, indicam que este último insistiu em efectuar uma distinção entre o nível existencial e existenciário no que concerne, por exemplo, à questão da

6 Todas as nossas citações remetem para Martin Heidegger, Sein und Zeit, Vittorio Klostermann, Frankfurt am Main,1977 (1. ${ }^{a}$ ed. 1927). Cf. a tradução de José Gaos, El Ser y el Tiempo, México, Fondo de Cultura Económica, 1977 (1. ${ }^{a}$ ed. 1951). 
morte. A observação que Heidegger faz a propósito de Kierkegaard (cf. § 45, em nota de rodapé), considerando que "os problemas existenciários lhe escaparam», embora tivesse feito observações interessantes ao nível existencial, podia também, parece-nos, ser dirigida ao próprio Ricoeur. Escreve Heidegger que «a exegese existenciária da morte é anterior a toda a biologia e ontologia da vida» (§ 49). A insistência de Heidegger neste ponto é manifesta, chegando mesmo a acrescentar, por exemplo, que «a análise ontológica do "ser relativamente a um fim" não prejudica, por outro lado, nenhuma posição existencial perante a morte» (ibid.). É assim que a psicologia, a metafísica ou a antropologia da morte, em nada alteram a sua concepção, precisamente por esta se considerar anterior a todas estas perspectivas. Ao situar-se a um nível ontológico, Heidegger quer considerar a morte como um modo de ser do Dasein relativamente a um fim. Ora, só uma análise ontológico-existenciária permite mostrar a estrutura ontológica do Dasein, isto é, o facto de ser relativamente a um fim. Tudo aquilo que se possa dizer sobre a morte a um nível ôntico é devedor desta estrutura ontológica. Ser relativamente a um fim é considerar que a morte é iminente para o Dasein. Resta saber se será efectivamente possível distinguir a interpretação ontológica da morte, o "propriamente morrer», do modo ôntico de assumi-la. Não fará o próprio Heidegger, de forma sub-reptícia, um uso ôntico nas considerações que tece sobre esta ontologia da morte que se assume como radical?

Outra objecção, não menos premente, seria a de interrogar se podemos efectivamente pensar a finitude do Dasein sem que, simultaneamente, se assuma uma posição em relação à infinitude, o que remete o pensamento heideggeriano para o horizonte das categorias herdadas. Se, para Heidegger, a eternidade só pode ser um conceito derivado, pois a filosofia é em si mesma ateia, tal significa que o tempo só pode ser pensado a partir do próprio tempo. Repitamos que o Dasein não está no tempo; ele é o tempo. Deste modo, a noção de morte é de tal forma importante na concepção do autor de $S u Z$ que até o próprio sentido do «eu sou» se revela no facto do Dasein morrer. Como escreve algures Heidegger, «eu existo apenas porque vou morrer». É neste sentido que há um afastamento radical entre Heidegger e Ricoeur, o que equivale a dizer que aquilo que cada um deles pensa sobre a morte tem as suas repercussões em cada uma das perspectivas historiográficas que defendem ${ }^{7}$.

O que a exegese do Dasein mostra é que o cuidado se funda na temporalidade. Ao ser no mundo, o Dasein temporaliza-se, o que o revela não só como um ser relativamente a um fim como, em geral, um poder ser total. No $\S 72$ de $S u Z$ refere-se que o todo que o Dasein busca está entre o nascimento e a morte. É assim que para além de ser compreendido como antecipação em relação a fim (a morte), deve-se também compreendê-lo em relação a um ter sido. Deste modo, o Dasein prolonga-se entre o nascer e o morrer, formando uma continuidade que, na verdade, as páginas iniciais de $S u Z$ não tomaram em devida consideração. É, portanto, enquanto cuidado que o Dasein está entre - entre o nascer e o morrer. Designa-se por historicidade esta mobilidade do prolongar entre o nascer e o morrer. O Dasein faz-se no tempo, entre a vida e a morte, e é por isso que ele é, no fundo do seu ser, temporalidade.

É neste sentido que se justifica que não é na historiografia, na ciência da história, que se deve procurar o sentido da temporalidade. Ao invés, é na 
temporalidade mesma do Dasein que se deve procurar o sentido da história, pois esta última só pode ser objecto de uma historiografia se o Dasein estiver enraizado prioritariamente na temporalidade. É esta visão da história que originará uma profunda revisão dos conceitos vulgares que se têm dela. Se a historiografia procede ontologicamente da historicidade do Dasein, este último abre-se para o mundo e interpreta-se a partir de uma reiteração da sua temporalidade. Heidegger, porém, tem também o intuito de distinguir a historicidade própria da imprópria.

Façamos, desde já, um conjunto de observações. Com a finalidade de elucidar o que está em questão na leitura de $S u Z$ efectuada por Ricoeur, é pertinente acentuar que a noção de ser-para-a-morte, no contexto da relação entre temporalidade e historicidade, só é possível desde que se pressuponha o entre, isto é, o facto do Dasein estar lançado no mundo entre o que foi e o que será. Uma segunda observação desponta quando Heidegger sublinha que o fundamento da historicidade se encontra na temporalidade do Dasein e, por isso, no cuidado. Por fim, se o fundamento da historicidade se enraíza no Dasein, Ricoeur preferirá deslocar a fundamentação para o homem que age e sofre. Uma última e decisiva confrontação, que sintetiza as anteriores, leva-nos a interrogar o porquê da insistência de Ricoeur numa visão antropológica/epistemológica quando este não é, decididamente, o desiderato de Heidegger.

No $\S 73$ de $S u Z$ indica-se em que sentido pode a história ser ambígua. Sem a preocupação de sermos exaustivos, refira-se que podemos considerar a história enquanto "realidade histórica» ou ciência dessa realidade; podemos, ainda, se eliminarmos de momento a história no sentido de ciência, caracterizá-la como algo que designa o passado - aquilo que já não está «em face», ou então, «está em face» mas sem acção sobre o presente. Num outro sentido podemos ainda dizer que a história não designa tanto o passado mas sim o que procede do passado - e seria então uma acção continuada de acontecimentos que precedem do passado e se estendem para o presente e para o futuro. Por fim, Heidegger fala ainda da história como sendo o «tradicional» enquanto tal, algo que recebemos da tradição sob a forma do já compreendido.

Deste modo, se há coisas passadas tal significa que há coisas que utilizámos, das quais nos servimos, que estavam à mão - o que mostra, uma vez mais, que o passado nos remete para o cuidado como modo de estar no mundo do Dasein. Com efeito, este só é histórico se pertencer a um mundo - o que indica que o ter sido faz parte da temporalidade do Dasein. Mais: o ter sido temporaliza-se com a mesma originalidade que o presente e o futuro. Escreve Heidegger que «primariamente histórico - repetimos - é o Dasein» (§73).

No entanto, é de toda a importância fazer a distinção entre uma historicidade própria de uma outra, imprópria. Heidegger diz-nos que o Dasein, ao projectar-se nas suas possibilidades, antecipa-se. O existir próprio do Dasein assenta na resolução. Ora, o ser-para-a-morte é o ser para a finitude - e é nesse estado, precisamente, que o Dasein faz de si um destino individual. Como ser no mundo, o Dasein resolve-se a ser - embora saiba que é um destino com outros, isto é, que há um destino colectivo. Ora, como é que o Dasein se faz tradição? Ao estar lançado no mundo ele está projectado para o futuro e assume as possibilidades herdadas pela tradição. É por isso que se faz tradição reiterando uma possibilidade que foi, isto é, reitera uma tradição, resolvendo-se a ser relativamente a um fim, pois «o ser relativamente à morte própria, quer dizer, a finitude da temporalidade, é o fundamento oculto da historicidade do Dasein» (\$ 74).

Se esta é a historicidade própria do Dasein - que reitera a tradição resolvendo-se a ser, aberto para o mundo -, outra há em que o Dasein se perde no 
que se passa diariamente. É assim que na historicidade imprópria «é oculta a prolongação original do destino individual». Cego para as possibilidades, o Dasein não é capaz de reiterar o que foi.

3. O que ressalta da nossa reflexão é que a noção de tempo é, em Heidegger, marcada pela finitude. «A razão secreta da historialidade do Dasein» reside na sua finitude e, portanto, em ser-para-a-morte» (cf. § 65). Ou então, como escreve Heidegger no mesmo parágrafo de $S u Z$, «é apenas porque o tempo originário é finito que o tempo derivado pode temporalizar-se como in-finito». Repitamos que Ricoeur, ao não se situar nesta perspectiva, parte de pressupostos teóricos que se distinguem dos de Heidegger. Curiosamente, embora sem o referir expressamente em $L a$ Mémoire, L'histoire, L'oubli, a obra que nos serve de referência, Ricoeur está mais próximo de Kant do que do autor de SuZ.

Quando Christophe Bouton ${ }^{8}$, por exemplo, relaciona o problema da finitude do tempo em Kant e Heidegger, mostra a necessidade de diferenciar o tempo da "estética transcendental" do tempo prático que Kant considera fundamental para a compreensão do homem enquanto sujeito moral. A finitude do tempo é, para Kant, uma consequência inevitável para quem é dotado apenas de intuições derivadas e não originárias. Os objectos são dados na intuição, não são criados por ela, o que mostra que o tempo limita a apreensão dos fenómenos. Todavia, e embora Heidegger tenha assinalado a importância da finitude do tempo em Kant, não pensou aquilo que, na obra deste, faz apelo a um tempo prático, isto é, um tempo que tem de pressupor uma duração infinita para que a lei moral tenha efectivamente sentido. Ora, se a imortalidade da alma tem como postulado a infinitude do tempo, tal significa que o sujeito moral projecta-se sempre para fora dos seus limites. Foi esta dimensão do tempo que Heidegger não tomou em consideração na perspectiva kantiana. Escreve Bouton: «Na sua interpretação de Kant, Heidegger, deixando na sombra a dimensão prática do pensamento kantiano, desconheceu totalmente esta possibilidade de um tempo prático infinito, e ele não podia, a bem dizer, senão desconhecê-la, tanto ela se opõe à sua própria concepção da finitude» (art. cit. p. 69).

É por isso que nos parece essencial chamar a atenção para aquilo que Ricoeur escrevia no Conflito das Interpretações 9 sobre Kant em "A liberdade segundo a esperança". Por aí se vê a "continuidade» do pensamento ricoeuriano, pois a esperança e, portanto, a visão do futuro que se furta à noção de finitude heideggeriana, era já visível. Embora aborde, noutros contextos da sua obra, a noção de história, parece-nos que a «liberdade segundo a esperança» é essencial para a compreensão da sua filosofia e do lugar que a ética ocupa nela - o que não é de forma alguma preocupação de Heidegger. Escreve Ricoeur: «A esperança é ela mesma esperança da história; porque cada realização é percebida como confirmação, aposta e relance da promessa; esta propõe um acréscimo, um "ainda não", que mantém a tensão da história» (op. cit., p. 395).

É neste sentido que os horizontes de cada uma das concepções filosóficas, de Ricoeur e de Heidegger, se distinguem, o que nos permite compreender que os lugares em que cada uma dessas concepções se situa não se assemelha, isso apesar de Ricoeur confessar a sua admiração por Sein und Zeit e não cessar de dialogar com a sua filosofia, nomeadamente com as noções de história e tempo.

8 C. Bouton, "«Que m'est-il permis d'espérer?»: le problème de la finitude du temps chez Kant et Heidegger", Archives de Philosophie, 62, 1999.

9 Paul Ricoeur, Le conflit des interprétations. Essais d'herméneutique, Paris, Éditions du Seuil, 1969. 
